\title{
Prediction of ultimate stress in unbonded prestressed tendons
}

\author{
F. T. K. $\mathrm{Au}^{*}$ and J. S. Du* \\ University of Hong Kong
}

\begin{abstract}
The behaviour of prestressed concrete members with unbonded tendons is different from that of members with bonded tendons. While the behaviour of prestressed concrete beams with bonded tendons is characterised by that existing at individual sections, analysis of the entire member is necessary for beams with unbonded tendons. This paper examines various design methods for the determination of ultimate tendon stress at flexural failure of prestressed concrete beams with unbonded tendons. Two broad categories of deformation-based approaches have been identified, namely those based on the span-depth ratio together with loading type, and those based on the neutral axis depth. These methods are reviewed critically. A new design formula has been proposed in the light of the available experimental data. It is applicable not only to the conventional high-strength steel prestressing tendons, but also to those made of other materials such as fibre-reinforced polymer.
\end{abstract}

\section{Introduction}

The use of unbonded tendons in prestressing may be in the form of internal tendons in beams and slabs. They may also be in the form of external tendons both in new construction as well as retrofitting of concrete bridges. With the increasing use of unbonded tendons in prestressed concrete structures, there is a need for an examination of the design and analysis of such structures. Although prestressed concrete beams with bonded and unbonded tendons behave in a similar manner at the working stage, they behave much differently when overloaded. The behaviour of prestressed concrete beams with bonded tendons is characterised by that existing at individual sections, as there is bonding between the tendons and the surrounding concrete. However this is not the case for prestressed concrete beams with unbonded tendons because the tendons and the surrounding concrete generally move with respect to each other. The stress increase in the tendons due to external loading subsequent to prestressing depends on the deformation of the whole member, and it cannot be determined from the analysis of the cross section alone

\footnotetext{
* Department of Civil Engineering, The University of Hong Kong, Pokfulam Road, Hong Kong, PR China.
}

(MCR 1060) Paper received 18 July 2002; last revised 28 April 2003; accepted 2 June 2003. as in the case of bonded tendons. Therefore an analysis of the whole member is necessary. Many experimental and analytical studies had been carried out within the past five decades for prediction of flexural resistance of prestressed concrete beams with unbonded tendons, which is closely related to the ultimate tendon stress $f_{p s}$ at flexural failure. As a result, formulae of different sophistication have been suggested for the purpose. This paper critically reviews the existing design formulae and recommends a simpler approach in the light of the available experimental results.

\section{Existing literature}

Baker $^{1}$ was one of the pioneers who worked on the prediction of stress in unbonded tendons at the ultimate limit state. Since then, research work on the topic proliferated. $^{2-22}$ A comprehensive evaluation of the stateof-the-art up to 1991 was carried out by Naaman and Alkhairi, ${ }^{13}$ while Allouche et al. ${ }^{19}$ reported another comprehensive literature review of the topic up to 1998. A common approach in the prediction of the ultimate tendon stress $f_{p s}$ at flexural failure of a beam with unbonded tendons is to start with the effective prestress $f_{p e}$ and to determine the subsequent stress increment $\Delta f_{p s}$ due to any additional load leading to ultimate failure. Investigations over the past five decades have identified the factors that influence this 
stress increment to include the concrete compressive strength, amounts of prestressing tendons and nonprestressed reinforcement, the span-depth ratio, etc. Actually findings from these investigations have been instrumental in the continuous improvements in the formulae adopted in various design $\operatorname{codes}^{23-27}$ for prediction of the ultimate tendon stress $f_{p s}$ at flexural failure.

To predict the ultimate tendon stress $f_{p s}$ at flexural failure, Baker ${ }^{1}$ introduced the bond reduction coefficient $\lambda$, which is defined as the ratio of average concrete stress adjacent to the steel to the maximum concrete stress adjacent to the steel. For the ultimate limit state, he suggested a safe limiting value of $\lambda=0 \cdot 1$. After testing a number of simple prestressed concrete beams with unbonded tendons, Janney et al. ${ }^{2}$ suggested that the coefficient $\lambda$ be taken as the ratio of neutral axis depth $c$ at ultimate to the depth $d_{p}$ to prestressing tendon, i.e. $\lambda=c / d_{p}$. To investigate the effects of the amount of reinforcement, the concrete compressive strength and the type of loading on the ultimate behaviour, Warwaruk et al. ${ }^{3}$ tested 82 simply supported partially prestressed beams. Apart from recognising the role of supplementary reinforcement in crack control, a prediction formula was also suggested. Subsequently Pannell ${ }^{4}$ carried out comprehensive investigations to study the effects of the span-depth ratio, the effective prestress and the amount of reinforcement on the flexural behaviour of prestressed concrete beams with unbonded tendons. He put forward another prediction formula on the assumption that the width $L_{p}$ of the plastic zone at ultimate is $10 \cdot 5$ times the neutral axis depth $c$ at ultimate. To evaluate the effects of the presence or absence of bond, the amount of supplementary non-prestressed reinforcement, etc., Mattock et $a .^{5}$ tested a number of simple and continuous partially prestressed concrete beams, and critically examined the ACI design code prevalent at the time. The design code was subsequently amended in the light of such research findings. Later Tam and Pannell ${ }^{6}$ reported their findings on the effects of the amounts of prestressed and non-prestressed tensile steel, the spandepth ratio $L / d_{p}$ and the effective prestress $f_{p e}$. The investigations by Mojtahedi and Gamble ${ }^{7}$ identified the significant effect the span-depth ratio $L / d_{p}$ had on the ultimate tendon stress $f_{p s}$ at flexural failure. They also put forward a strut-and-tie model to support these observations. The work of Burns et al. ${ }^{8}$ on one-way prestressed concrete continuous slabs suggested that the loading arrangement, the pattern of plastic hinge formation and the span-depth ratio all have effects on the ultimate behaviour of such structures. The experimental and analytical investigations by Cooke et al. ${ }^{9}$ were mainly to study the effect of the span-depth ratio and the amount of prestressing steel on the stress $f_{p s}$ in unbonded tendons at ultimate. They also critically reviewed various versions of the existing ACI design code and recommended certain amendments. In a bid to show the significance of non-prestressed reinforce- ment and its effect on the ultimate tendon stress $f_{p s}$ at flexural failure, $\mathrm{Du}$ and $\mathrm{Tao}^{10}$ carried out an experimental investigation and proposed a revised design formula to take this into account. In the analytical investigation undertaken by Harajli ${ }^{11}$ to study the effect of loading type and span-depth ratio on the ultimate tendon stress $f_{p s}$ at flexural failure, the span-depth ratio was incorporated into the design formula in ACI $318-83 .^{23}$ A revised design formula that could allow for a continuous transition for various span-depth ratios was proposed. Various research groups also focused on the improvement of design formulae adopted in different design codes. They include Campbell and Chouinard, $^{12}$ Naaman and Alkahiri, ${ }^{13,14}$ Harajli and $\mathrm{Kanj}^{15}$ and Chakrabarti. ${ }^{16}$

\section{Design approach based on span-depth ratio together with loading type}

Figure 1(a) shows a simply supported prestressed concrete beam with unbonded tendons of span $L$, under the action of a pair of symmetrically disposed point loads separated by a distance $L_{a}$. The actual and idealised distributions of curvature developed at the nominal flexural strength of the beam are shown in Fig. 1(b).

There are three major simplifying assumptions adopted by various researchers. ${ }^{5,11,20}$

(a) Although the strain in the unbonded prestressing steel is incompatible with that of the surrounding concrete, the total elongation of the prestressing steel between the end anchorages can be determined from the curvature distribution along the beam length.

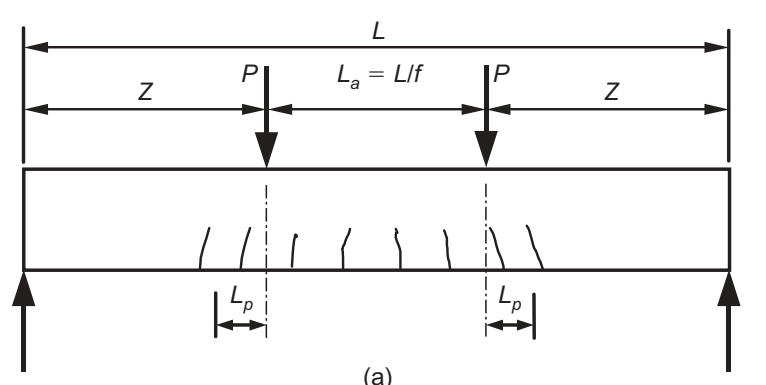

(a)

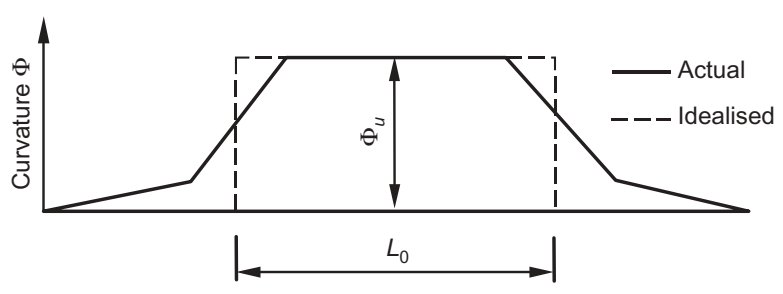

(b)

Fig. 1. A simply supported prestressed concrete beam with unbonded tendons under two symmetrically disposed point loads: (a) arrangement of loading; (b) actual and idealised curvature distribution along the beam 
(b) The total elongation of the prestressing steel between the end anchorages is mainly caused by the plastic deformation occurring with of plastic region of length $L_{0}$ in the idealised curvature distribution shown in Fig. 1(b), whereas the deformation within the elastic regions is neglected.

(c) Any frictional stresses acting along the tendons are negligible so that the stress in the unbonded tendons is constant along the beam length.

In other words, it is assumed that the increase in tendon elongation between the end anchorages, and therefore the corresponding stress increment in the prestressing tendons, is mainly due to the plastic deformation occurring within an equivalent plastic region length $L_{0}$ in the vicinity of applied load (Fig. 1(b)).

The strain distribution across the section depth of a prestressed concrete beam with unbonded tendons is shown in Fig. 2. Let $\Delta \varepsilon$ be the 'fictitious' increase in strain above decompressive strain in the concrete at the level of prestressing tendon, $\varepsilon_{p e}$ be the effective prestrain of the tendon, $\varepsilon_{c e}$ be the precompressive strain in the concrete at the level of prestressing tendon and $\varepsilon_{c u}$ be the ultimate concrete compressive strain in the top fibre which is taken as 0.003 as specified in the ACI Building Code. $^{23}$ Therefore the 'fictitious' strain increment $\Delta \varepsilon$, the total increase in tendon elongation between the end anchorages $\Delta l_{p s}$ and the increase in strain $\Delta \varepsilon_{p s}$ in the prestressing tendon above effective prestrain can be expressed respectively as follows

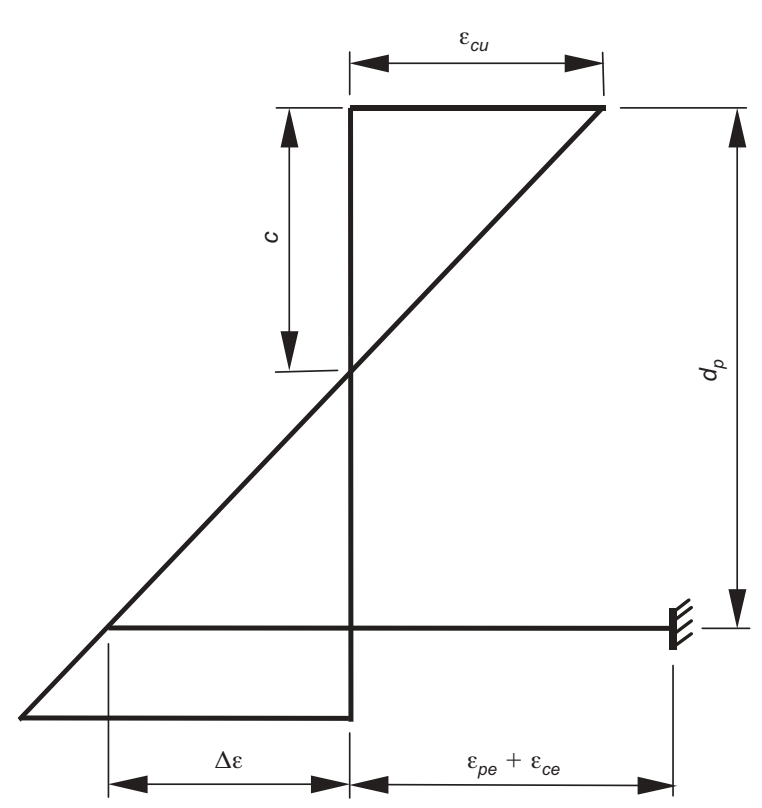

Fig. 2. Strain distribution across the section depth of a prestressed concrete beam with unbonded tendons

$$
\begin{aligned}
\Delta \varepsilon & =\left(\frac{d_{p}-c}{c}\right) \varepsilon_{c u} \\
\Delta l_{p s} & =\left(\Delta \varepsilon+\varepsilon_{c e}\right) L_{0} \\
\Delta \varepsilon_{p s} & =\Delta l_{p s} / L
\end{aligned}
$$

where $L_{0}$ is the equivalent length of plastic region in the member as shown in Fig. 1(a) and $L$ is total span length between the end anchorages. The strain $\varepsilon_{p s}$ in the prestressing tendon at nominal flexural strength can be obtained by combining equations (1), (2) and (3) as

$$
\begin{aligned}
\varepsilon_{p s}= & \varepsilon_{p e}+\Delta \varepsilon_{p s}=\varepsilon_{p e}+\varepsilon_{c e}\left(\frac{L_{0}}{L}\right) \\
& +\varepsilon_{c u}\left(\frac{d_{p}-c}{c}\right)\left(\frac{L_{0}}{L}\right)
\end{aligned}
$$

The unbonded tendon usually remains elastic and therefore the stress $f_{p s}$ can be expressed as

$$
\begin{aligned}
f_{p s} & =E_{p s} \varepsilon_{p s}=E_{p s} \varepsilon_{p e}+E_{p s} \Delta \varepsilon_{p s} \\
& =f_{p e}+E_{p s} \varepsilon_{c e}\left(\frac{L_{0}}{L}\right)+E_{p s} \varepsilon_{c u}\left(\frac{d_{p}-c}{c}\right)\left(\frac{L_{0}}{L}\right)
\end{aligned}
$$

where $E_{p s}$ is the modulus of elasticity of prestressing tendon and $f_{p e}$ is the effective prestress. Generally the value of $\varepsilon_{c e}$ is negligible compared to the other terms. Thus neglecting $\varepsilon_{c e}$, equation (5) can be written in terms of the stress increment $\Delta f_{p s}$ caused by additional loading to reach the ultimate moment condition as

$$
f_{p s}=f_{p e}+\Delta f_{p s}=f_{p e}+E_{p s} \varepsilon_{c u}\left(\frac{d_{p}-c}{c}\right)\left(\frac{L_{0}}{L}\right)
$$

The neutral axis depth $c$ at the critical section at ultimate can be computed from equation (6) as

$$
c=\frac{E_{p s} \varepsilon_{c u}\left(L_{0} / L\right) d_{p}}{\Delta f_{p s}+E_{p s} \varepsilon_{c u} L_{0} / L}
$$

If the member is of flanged section, the force equilibrium equation at the critical section can be written as

$$
\begin{aligned}
& A_{p s} f_{p s}+A_{s} f_{y}-A_{s}^{\prime} f_{y}^{\prime}=0 \cdot 85 \beta_{1} f_{c}^{\prime} b_{w} c+C_{f} \\
& \begin{cases}C_{f}=0 \cdot 85 \beta_{1} f_{c}^{\prime}\left(b-b_{w}\right) h_{f} & \text { if } \beta_{1} c>h_{f} \\
C_{f}=0, b_{w}=b & \text { if } \beta_{1} c \leqslant h_{f}\end{cases} \\
& \begin{cases}\beta_{1}=0.85 & \text { if } f_{c}^{\prime}<28 \mathrm{MPa} \\
\beta_{1}=0.85-0.05\left(f_{c}^{\prime}-28\right) / 7 & \text { if } 28 \mathrm{MPa} \leqslant f_{c}^{\prime} \leqslant 56 \mathrm{MPa} \\
\beta_{1}=0.65 & \text { if } f_{c}^{\prime}>56 \mathrm{MPa}\end{cases}
\end{aligned}
$$

where $A_{p s}$ is the cross sectional area of prestressing tendon; $A_{s}$ and $f_{y}$ are respectively the cross sectional area and yield strength of ordinary tension reinforcement; $A_{s}^{\prime}$ and $f_{y}^{\prime}$ are, respectively, the cross sectional area and yield strength of ordinary compression reinforcement, $f_{c}^{\prime}$ is the cylinder compressive strength of concrete; $b$ and $b_{w}$ are, respectively, the breadths of flange and web; $C_{f}$ is the compressive force carried by 
the flange if applicable; and $\beta_{1}$ is the concrete compression block reduction factor. ${ }^{23,25,27}$ The tendon stress $f_{p s}$ at ultimate can be obtained by substituting the value of $c$ from equation (7) into equation (8a) and invoking equation (6) as ${ }^{11}$

$$
\begin{aligned}
f_{p s}= & \frac{1}{A_{p s}} \frac{0 \cdot 85 \beta_{1} f_{c}^{\prime} b_{w}\left(L_{0} / L\right) d_{p} E_{p s} \varepsilon_{c u}}{f_{p s}-f_{p e}+E_{p s} \varepsilon_{c u}\left(L_{0} / L\right)} \\
& +\frac{\left(A_{s}^{\prime} f_{y}^{\prime}-A_{s} f_{y}\right)+C_{f}}{A_{p s}}
\end{aligned}
$$

The equivalent length $L_{0}$ of the plastic region can be obtained as shown in Fig. 1 as

$$
L_{0}=L_{a}+2 L_{p}=L / f+2 L_{p}
$$

where $f$ is a coefficient dependent on the arrangement of loading. Harajli ${ }^{11}$ suggested $f=\infty$ for single concentrated load, $f=3$ for two third-point concentrated loads and $f=6$ for uniform loading. The second term $2 L_{p}$ in equation (10) is the plastic hinge length measured outside the constant moment region. The parameter $L_{p}$ is taken as

$$
L_{p}=0 \cdot 5 d_{p}+0 \cdot 05 Z
$$

where $Z$ is the shear span or the distance between the point of maximum moment and the point of contraflexure as shown in Fig. 1(a). An expression for $L_{0}$ is obtained by substituting the value of $L_{p}$ from equation (11) into equation (10)

$$
L_{0}=d_{p}\left[\frac{L}{d_{p}}\left(\frac{0 \cdot 95}{f}+0 \cdot 05\right)+1 \cdot 0\right]
$$

which appears in dimensionless form as

$$
L_{0} / L=\frac{0.95}{f}+0.05+\frac{1}{L / d_{p}}
$$

Harajli ${ }^{11}$ examined the validity of the above model by comparing his results with the experimental results of the tendon stress $f_{p s}$ at ultimate obtained by Warwaruk et al., ${ }^{3}$ Mattock et al., ${ }^{5}$ and Du and Tao ${ }^{10}$ concluding that equation (9) reproduced fairly accurately the experimental results.

\section{Further study of equivalent length of plastic region $L_{0}$}

As the validity of the previous approach relies on the determination of the equivalent length $L_{0}$ of plastic region, it is useful to verify this model by comparing the theoretical value of $L_{0} / L$ from equation (13) against the experimental values. Rearranging equation (9), the experimental value of $L_{0} / L$ can be obtained as
$\frac{L_{0}}{L}$

$=\frac{\left(A_{p s} f_{p s}+A_{s} f_{y}-A_{s}^{\prime} f_{s}^{\prime}-C_{f}\right)\left(f_{p s}-f_{p e}\right)}{\left(0.85 f_{c}^{\prime} \beta_{1} b_{w} d_{p}-A_{p s} f_{p s}-A_{s} f_{y}+A_{s}^{\prime} f_{c}^{\prime}+C_{f}\right) E_{p s} \varepsilon_{c u}}$

Based on the findings of $\mathrm{Du}$ and Tao ${ }^{10}$ and Harajli and $\mathrm{Kanj}^{15}$ the theoretical values of $L_{0} / L$ from equation (13) are plotted against the experimental values from equation (14) in Fig. 3. It is observed that there is much disagreement between theoretical and experimental values of $L_{0} / L$.

All test beams of Du and Tao ${ }^{10}$ were $160 \times 280 \mathrm{~mm}$ in cross section, $4400 \mathrm{~mm}$ in length, and were tested with two symmetrical third-point loads over a $4200 \mathrm{~mm}$ span. The span-depth ratio was kept constant at 20, while the compressive strength of concrete, the cross sectional areas of prestressing and ordinary steel were varied. The theoretical values of $L_{0} / L$ for all specimens were $0 \cdot 42$, whereas the experimental values ranged from $0 \cdot 17$ to $0 \cdot 88$. The mean value of $L_{0} / L$ is $0 \cdot 34$ based on 20 beams, while the standard deviation is $0 \cdot 16$ with a coefficient of variation as high as $0 \cdot 47$. In the experiment of Harajli and Kanj, ${ }^{15}$ a total of 26 simply supported beams with rectangular cross section were tested. The main input parameters included three different contents of tension reinforcement, two different amounts of ordinary steel relative to the prestressing steel (fully prestressed and partially prestressed), and three different values of span-depth ratio $(20,13$ and 8). For each set of input parameters, two specimens were tested, with one under single concentrated load at midspan, and the other under two symmetrical thirdpoint loads. The theoretical values of $L_{0} / L$ for beams with span-depth ratios 20,13 , and 8 under third-point loads are $0.42,0.44$, and 0.48 respectively; whereas for those under single concentrated load at midspan, they are $0 \cdot 10,0 \cdot 13$, and $0 \cdot 17$ respectively. The experimental values of $L_{0} / L$ lie between 0.02 and 0.25 with a mean value of $0 \cdot 14$. The standard deviation is $0 \cdot 06$, while the

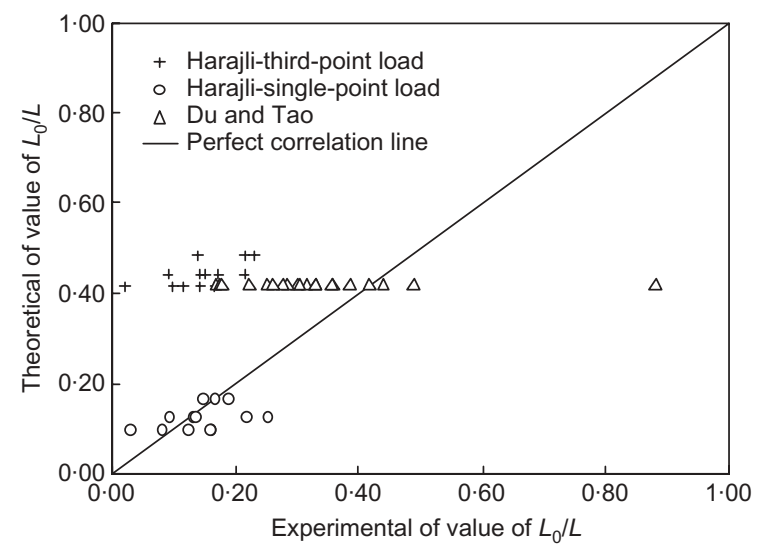

Fig. 3. Comparision of theoretical values against experimental values of $L_{0} / L$

Magazine of Concrete Research, 2004, 56, No. 1 
coefficient of variation is $0 \cdot 43$. In addition, the experimental values of $L_{0} / L$ for members tested under single concentrated load are comparable in magnitude to their counterparts tested under two third-point loads. This phenomenon is consistent with the measurements of the tendon stress $f_{p s}$ at ultimate by Harajli and Kanj, ${ }^{15}$ but in contradiction with those computed from equation (13). This discrepancy is obviously caused by the use of the coefficient $f$ that relies entirely on the loading type. On closer examination of Harajli's model, ${ }^{11}$ one may discover that the factor $L_{0} / L$ is very much similar to the bond reduction coefficient $\lambda$ which Baker ${ }^{1}$ suggested should be determined experimentally.

Recently, Lee et al. ${ }^{20}$ further worked on Harajli's model $^{11}$ to derive another design equation for the evaluation of the tendon stress $f_{p s}$ at ultimate. In particular, the term $0.05 Z$ in equation (11) was neglected. The coefficient $f$ to account for type of loading is also different, i.e. $f=10$ for one-point loading, and $f=3$ for two-point loading or uniform loading. A moment equilibrium equation was used to replace the force equilibrium equation of the original model to take into account the geometrical locations of tendons and bonded reinforcement. An equation similar to equation (9) was obtained as follows

$$
\begin{aligned}
f_{p s}= & \frac{1}{\alpha_{p} A_{p s}} \frac{0 \cdot 85 \beta_{1} f_{c}^{\prime} b\left(L_{0} / L\right) d_{p} E_{p s} \varepsilon_{c u}}{f_{p s}+E_{p s} \varepsilon_{c u}\left(L_{0} / L\right)} \\
& +\frac{\left(A_{s}^{\prime} f_{y}^{\prime}-\alpha_{s} A_{s} f_{y}\right)}{\alpha_{p} A_{p s}} \\
\alpha_{p}= & \left(d_{p}-\beta_{1} c / 2\right) /\left(d_{e}-\beta_{1} c / 2\right) \\
\alpha_{s}= & \left(d_{s}-\beta_{1} c / 2\right) /\left(d_{e}-\beta_{1} c / 2\right) \\
d_{e}= & \left(A_{p s} f_{p s} d_{p}+A_{s} f_{y} d_{s}\right) /\left(A_{p s} f_{p s}+A_{s} f_{y}\right)
\end{aligned}
$$

where $d_{s}$ is the depth from the concrete extreme compressive fibre to the centroid of non-prestressed tensile steel. Introducing four new coefficients $K_{1}, K_{2}, K_{3}$ and $K_{4}$, Lee et $a l^{20}$ simplified equation (15) as follows

$$
\begin{aligned}
f_{p s}= & K_{1}+K_{2} f_{p e}+K_{3} \frac{\left(A_{s}^{\prime} f_{y}^{\prime}-A_{s} f_{y}\right)}{A_{p s}} \\
& +K_{4} \sqrt{\frac{d_{s}}{d_{p}} \frac{f_{c}^{\prime}}{\rho_{p}}\left[\frac{1}{f}+\frac{1}{L / d_{p}}\right]}
\end{aligned}
$$

The new coefficients $K_{1}, K_{2}, K_{3}$ and $K_{4}$ were found by regression analysis using previous test results. Incorporating a suitable safety margin, a design equation was obtained as

$$
\begin{aligned}
f_{p s}= & 10000+0 \cdot 8 f_{p e}+\frac{1}{15} \frac{\left(A_{s}^{\prime} f_{y}^{\prime}-A_{s} f_{y}\right)}{A_{p s}} \\
& +80 \sqrt{\frac{d_{s}}{d_{p}} \frac{f_{c}^{\prime}}{\rho_{p}}\left[\frac{1}{f}+\frac{1}{L / d_{p}}\right]} \text { psi } \\
f_{p e}+ & 10000 \leqslant f_{p s} \leqslant f_{p y} \text { psi }
\end{aligned}
$$

To ascertain the accuracy of equation (17), Lee et $a l^{20}$ carried out regression analysis and worked out the correlation coefficient $R$ between the stress increases $\Delta f_{p s}$ in the unbonded tendons predicted by equation (17) and the experimental results available then. Lee et al. ${ }^{20}$ concluded that their design formula (i.e. equation (17) $)(R=0.77)$ was better than the design formulae of the ACI 318-95 $\operatorname{code}^{27}(R=0.64)$, Harajli and $\mathrm{Kanj}^{15}(R=0.55)$, Chakrabarti ${ }^{16} \quad(R=$ $0.64)$ and the AASHTO LRFD $\operatorname{code}^{25}(R=0.71)$. However one must bear in mind that the performance of equation (17) relies on the values of the coefficients $K_{1}, K_{2}, K_{3}$ and $K_{4}$ that have been determined by regression analysis using previous test results as well. Therefore using regression analysis alone as a selection criterion is likely to obscure the validity of the supporting theory, as it may favour methods with input also based on regression analysis.

\section{Design approach based on neutral axis depth}

From the research work in the past five decades on the ultimate behaviour of prestressed concrete beams with unbonded tendons, it is indisputable that the tendon stress $f_{p s}$ at ultimate depends mainly on the equivalent length $L_{0}$ of plastic region in the member. A main school of thought is to determine $L_{0}$ with input of span-depth ratio together with loading type as described in the previous sections. Another school of thought is to relate $L_{0}$ to the neutral axis depth $c$. Actually as early as in 1969 , Pannell ${ }^{4}$ found that the ratio $\varphi$ of equivalent length of plastic region $L_{0}$ to neutral axis depth at ultimate $c$, namely $\varphi=L_{0} / c$, was a constant value for prestressed concrete beams with unbonded tendons even for different span-depth ratios. He also suggested taking $\varphi$ as 10, i.e. $L_{0}=10 \mathrm{c}$ for design purpose. Since then, different investigators around the world have conducted many tests on prestressed concrete beams with unbonded tendons. It is therefore useful to revisit this approach based on these experiments.

According to this approach, ${ }^{4,6}$ the extension of prestressing tendon $\Delta l_{p s}$ over the length of the equivalent plastic region is given by

$$
\Delta l_{p s}=L_{0} \varepsilon_{c u}\left(\frac{d_{p}-c}{c}\right)=\varphi \varepsilon_{c u}\left(d_{p}-c\right)
$$

and therefore, assuming the unbonded tendons remain elastic, the tendon stress $f_{p s}$ at ultimate appears as 


$$
\begin{aligned}
f_{p s} & =f_{p e}+\Delta f_{p s}=f_{p e}+E_{p s} \frac{\Delta l_{p s}}{L} \\
& =f_{p e}+\frac{\varphi E_{p s} \varepsilon_{c u}\left(d_{p}-c\right)}{L}
\end{aligned}
$$

Eliminating the neutral axis depth at ultimate $c$ between equation (19) and the force equilibrium equation of equation (8a) at the critical section, a general equation of $\varphi$ can be obtained as

$$
\varphi=\frac{\left(f_{p s}-f_{p e}\right) L}{E_{p s} \varepsilon_{c u} d_{p}\left(1-\frac{A_{p s} f_{p s}+A_{s} f_{y}-A_{s}^{\prime} f_{y}^{\prime}-C_{f}}{0 \cdot 85 \beta_{1} f_{c}^{\prime} b_{w} d_{p}}\right)}
$$

In other words, as long as the parameter $\varphi$ can be determined, the value of the tendon stress $f_{p s}$ at ultimate can be obtained by rearranging equation (20) as follows

$$
\begin{aligned}
& f_{p s}=f_{p e}+\Delta f_{p s} \\
& =f_{p e}+\frac{\varphi E_{p s} \varepsilon_{c u}\left(d_{p}-c_{p e}\right)}{L} /\left(1+\frac{\varphi E_{p s} A_{p s} \varepsilon_{c u}}{0 \cdot 85 \beta_{1} f_{c}^{\prime} b_{w} L}\right) \\
& c_{p e}=\frac{A_{p s} f_{p e}+A_{s} f_{y}-A_{s}^{\prime} f_{y}^{\prime}-C_{f}}{0 \cdot 85 \beta_{1} f_{c}^{\prime} b_{w}} \\
& c=c_{p e}+\frac{A_{p s} \Delta f_{p s}}{0.85 \beta_{1} f_{c}^{\prime} b_{w}} \\
& \begin{cases}C_{f}=0.85 \beta_{1} f_{c}^{\prime}\left(b-b_{w}\right) h_{f} & \text { if } \beta_{1} c>h_{f} \\
C_{f}=0, b_{w}=b & \text { if } \beta_{1} c \leqslant h_{f}\end{cases}
\end{aligned}
$$

In the study, Pannell ${ }^{4}$ tested 38 simply supported beams in three sets having span-depth ratios of 27, 40 and 12 respectively. Taking $E_{p s}$ as $212 \mathrm{kN} / \mathrm{mm}^{2}$ based on tests of the prestressing steel and $\varepsilon_{c u}$ as $0.325 \%$, values of the parameter $\varphi$ had been obtained for the test series using equation (20). From results of the parameter $\varphi$ for 32 beams, the mean was $12 \cdot 4$, and the standard deviation was 3.6 with a coefficient of variation of 0.29 as listed in Table 1 . He noted that $\varphi$ was reasonably constant for the whole series of tests, if it was borne in mind that inaccuracies in the measurements of $f_{p s}$ and $f_{p e}$ would cause magnified inaccuracies in $\varphi$. Strictly speaking the parameter $\varphi$ depends on all variables on the right-hand side of equation (20) as well as the type of loading. In the light of the test results, it appeared reasonable to conclude that a single value of $\varphi=12$ was appropriate over the whole range. As $\varphi=12$ was close to the mean value of the test results, Pannell suggested a safe value of $\varphi=10$, together with $\varepsilon_{c u}=0.0033$ and $E_{p s}=210 \mathrm{kN} / \mathrm{mm}^{2}$ for design purposes, which gave $\varphi E_{p s} \varepsilon_{c u} \cong 7000 \mathrm{~N} / \mathrm{mm}^{2}$. Actually the work of Pannell ${ }^{4}$ subsequently formed the basis of the British Code BS $8110^{24}$ and the Canadian Code A23.3-94 ${ }^{26}$ for determination of the tendon stress $f_{p s}$ at ultimate.

The Canadian Code A23.3-94 ${ }^{26}$ gives

$$
\begin{aligned}
f_{p s} & =f_{p e}+8000 \frac{\left(d_{p}-c_{y}\right)}{l_{e}} \leqslant f_{p y} \mathrm{MPa} \\
c_{y} & =\frac{A_{p s} f_{p y}+A_{s} f_{y}}{\alpha_{1} f_{c}^{\prime} \beta_{0} b} \\
\alpha_{1} & =0.85-0.0015 f_{c}^{\prime} \\
\beta_{0} & =0.97-0.0025 f_{c}^{\prime}
\end{aligned}
$$

where $l_{e}$ is the length of the tendon between the end anchorages divided by the number of plastic hinges required to develop a failure mechanism in the span under consideration, and $f_{p y}$ is the yield strength of prestressing tendons.

On the other hand, the British Code BS $8110^{24}$ recommends the following equation

$$
f_{p s}=f_{p e}+\frac{7000}{L / d_{p}}\left(1-\frac{1 \cdot 7 f_{p u} A_{p s}}{f_{c u} b d_{p}}\right) \leqslant 0.7 f_{p u} \mathrm{MPa}
$$

where $f_{c u}$ is the concrete compression strength taken from cube and $f_{p u}$ is the ultimate strength of prestressing tendons.

Comparing equations (22) and (23) with equation (21), it is not difficult to identify the differences among them. Equation (22) omits the term of $\varphi E_{p s} \varepsilon_{c u} A_{p s} /$ $0 \cdot 85 \beta_{1} f_{c}^{\prime} b_{w} L$, and it increases the value of $\varphi E_{p s} \varepsilon_{c u}$ from $7000 \mathrm{~N} / \mathrm{mm}^{2}$ to $8000 \mathrm{~N} / \mathrm{mm}^{2}$. It also takes into account the influence of indeterminate members. Equation (23) ignores the influence of ordinary reinforcement and simplifies the calculation of neutral axis depth $c$.

Table 1. Statistics of the parameter $\varphi$ based on results from different investigators

\begin{tabular}{l|c|c|c|c}
\hline Authors & No. of beams & Mean & Standard deviation & Coefficient of variation \\
\hline Pannell $^{4}$ & 32 & $12 \cdot 4$ & $3 \cdot 6$ & $0 \cdot 29$ \\
Tam and Pannell $^{6}$ & 8 & $10 \cdot 8$ & $1 \cdot 7$ & $0 \cdot 15$ \\
Cooke et al. $^{9}$ & 9 & $17 \cdot 3$ & $2 \cdot 5$ & $0 \cdot 15$ \\
Du and Tao $^{\text {Campbell and Chouinard }}{ }^{12}$ & 20 & $21 \cdot 4$ & $3 \cdot 3$ & $0 \cdot 16$ \\
Harajli and Kanj $^{15}$ & 6 & $15 \cdot 7$ & $1 \cdot 8$ & $0 \cdot 27$ \\
Chakrabarti $^{16}$ & 26 & $10 \cdot 5$ & $2 \cdot 9$ & $0 \cdot 39$ \\
Tan and Ng, $^{17}$ and Tan et al. $^{22}$ & 33 & $21 \cdot 7$ & $8 \cdot 4$ & $0 \cdot 24$ \\
Aparicio et al. & 10 & $19 \cdot 4$ & $4 \cdot 6$ & $0 \cdot 04$ \\
All & 4 & $10 \cdot 1$ & $0 \cdot 42$ & $0 \cdot 42$ \\
\hline
\end{tabular}


Later in 1976, Tam and Pannell ${ }^{6}$ tested eight partially prestressed concrete beams with unbonded tendons having span-depth ratios between 20 and 45 under single concentrated load at midspan. The values of $\varphi$ obtained from the tests were still fairly constant. The mean value of $\varphi$ for eight beams was $10 \cdot 8$, with a standard deviation of 1.7 and a coefficient of variation of $0 \cdot 15$. Based on such results, they suggested taking $\varphi$ as 10.5 for practical use.

\section{Further investigation of the parameter $\varphi$}

A crucial issue to address then is whether the parameter $\varphi$ can be effectively treated as constant, as suggested by Pannell ${ }^{4}$ and Tam and Pannell. ${ }^{6}$ Therefore the parameter $\varphi$ is further studied by examination of the test results from different investigators. In the analysis using equation (20), $\varepsilon_{c u}$ is taken as 0.003 , and $E_{p s}$ of the prestressing tendon is either taken as the test value in specific experiment or assumed to be $E_{p s}=200000 \mathrm{~N} / \mathrm{mm}^{2}$ in the absence of test data. The statistics of the parameter $\varphi$, which include the mean, standard deviation and coefficient of variation, are calculated for various sets of available experimental results. The standard deviation and the dimensionless coefficient of variation are both a measure of the spread of distribution. The statistics of the parameter $\varphi$ for experimental results from nine investigators are summarised in Table 1, while the relative frequency histogram is shown in Fig. 4. All these specimens are simply supported beams and slabs, reinforced with or without supplementary bonded reinforcement, and having a wide range of member span-depth ratios ranging from 8 to 45 . It should be mentioned that the tests of Tan and $\mathrm{Ng},{ }^{17}$ and Tan et al. ${ }^{21}$ consisted of two separate parts. The first part focused on the effects of deviators and tendon configuration on the behaviour of externally prestressed beams. The second part focused on the behaviour of simple-span reinforced concrete beams locally strengthened with external tendons. Five under-strength reinforced concrete beams were

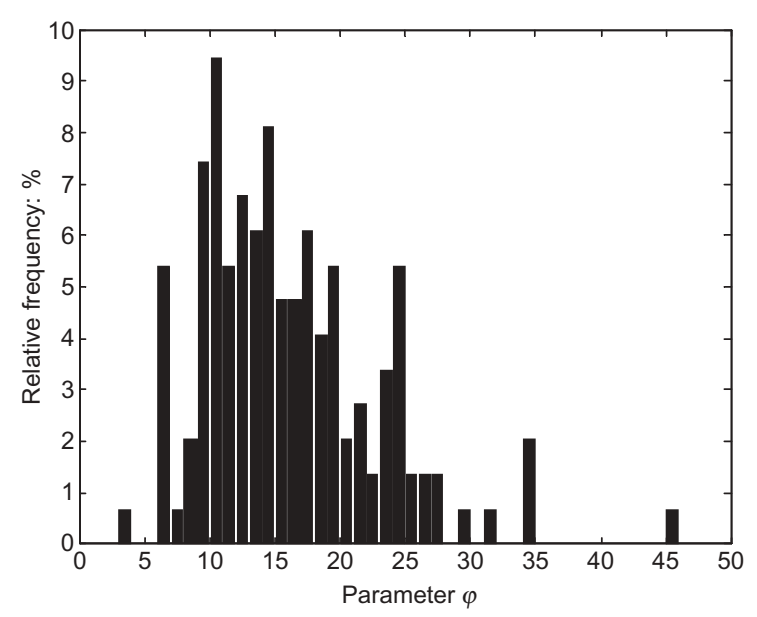

Fig. 4. Relative frequency histogram for the parameter $\varphi$ strengthened with steel or carbon fibre-reinforced polymer tendons and tested to failure under third-point loading. In the study by Aparicio et al. ${ }^{22}$ three were externally prestressed monolithic beams, and one was an externally prestressed segmental beam.

It can be observed from Table 1 and Fig. 4 that, although variation of the parameter $\varphi$ does exist, generally speaking the values are stable and they tend to be constant in a specific series of tests. The mean, standard deviation and coefficient of variation of the parameter $\varphi$ for 148 simply supported specimens are $16 \cdot 1,6 \cdot 8$ and $0 \cdot 42$ respectively. It should be pointed out that the mean value, standard deviation and coefficient of variation of parameter $\varphi$ obtained by Chakrabarti's test $^{16}$ are excessively larger than those of other tests. The difference of techniques and methods of measurement, variation of material properties as well as failure criteria of specimens adopted by different investigators may also cause the spread of results. In view of the above, it is not unreasonable to take the parameter $\varphi$ as a constant value in prestressed concrete flexural members with unbonded tendons.

Rearranging equation (19), the parameter $\varphi$ can be expressed in terms of the others as

$$
\varphi=\frac{\Delta f_{p s}}{E_{p s} \varepsilon_{c u}\left(d_{p} / L\right)\left(1-c / d_{p}\right)}
$$

It can be observed that, if the relationship between the stress increment $\Delta f_{p s}$ and the parameters $\left(L / d_{p}\right)$ and $\left(1-c / d_{p}\right)$ is linear or approximately linear, the parameter $\varphi$ could be a constant. Actually the parameter $c / d_{p}$ has already reflected the information on the design, with the exception of the span-depth ratio $L / d_{p}$. The tests conducted by Du and Tao, ${ }^{10}$ and Campbell and Chouinard ${ }^{12}$ indicted that the stress increment $\Delta f_{p s}$ increases with the decrease of $c / d_{p}$. Du and Tao ${ }^{10}$ also introduced the parameter $q_{0}=\left(A_{p s} f_{p e}+A_{s} f_{y}\right) /$ $b d_{p} f_{c}^{\prime}$ that was a measure of steel content including prestressed and non-prestressed steel. For a rectangular section and neglecting the contribution from compression reinforcement, $q_{0}$ somehow reflects the force equilibrium across the depth of the section and it is approximately proportional to $c / d_{p}$. Based on regression of their experimental data, Du and Tao ${ }^{10}$ established a linear relation between the stress increment $\Delta f_{p s}$ and the parameter $q_{0}$. In the tests of $\mathrm{Du}$ and Tao, ${ }^{10}$ Campbell and Chouinard ${ }^{12}$ and Aparicio et al., ${ }^{22}$ the span-depth ratios were kept constant, while parameter $q_{0}$ was varied. As shown in Table 1, the coefficients of variation of the parameter $\varphi$ are relatively small, which are $0 \cdot 16,0 \cdot 11$, and $0 \cdot 04$ respectively.

Regarding the influence of the span-depth ratio on the stress increment $\Delta f_{p s}$, Mojtahedi and Gamble ${ }^{7}$ proposed a strut-and-tie model, which showed that the strain, and hence the stress, of unbonded tendons decreased as the span-depth ratio $L / d_{p}$ increased. Harajli and $\mathrm{Kanj}^{15}$ worked on a similar topic and found it 
difficult to draw accurate conclusions because of the dependence of the stress increment $\Delta f_{p s}$ on other design parameters such as the content of tension reinforcement and concrete strength. However, an overall global reduction in the stress increment $\Delta f_{p s}$ with increasing span-depth ratio could indeed be observed. Analysis of the parameter $\varphi$ from the results of Harajli and $\mathrm{Kanj}^{15}$ shows that it drops slightly with the decrease of span-depth ratio. However in the tests by Tam and Pannell, ${ }^{6}$ and Cooke et al., ${ }^{9}$ no clear trend of variation with the span-depth ratio is observed. This may be caused by different testing techniques such as load arrangement, use of strands or wire enclosed in large steel ducts or small plastic ducts, prestress load measuring techniques and tendon profiles.

\section{Proposed method}

This paper advocates the adoption of Pannell's approach $^{4}$ with the determination of a reasonable value for the parameter $\varphi$. Three different values of $\varphi$ are studied here, namely $(a)$ the mean value of the parameter $\varphi$ in Table $1(\varphi=16 \cdot 1),(b)$ the original value of Pannell $^{4}(\varphi=10)$, and $(c)$ the mean minus one standard deviation of the parameter $\varphi$ in Table 1 $(\varphi=16 \cdot 1-6 \cdot 8=9 \cdot 3)$. Values of the tendon stress $f_{p s}$ at ultimate are again calculated by equation (21) with the above three values of $\varphi$ together with the limit $f_{p s} \leqslant f_{p y}$. Correlation analyses of the tendon stress $f_{p s}$ at ultimate were subsequently carried out between the experimental results and the calculated values based on the three cases of $\varphi$ values. The correlation coefficients for the three cases are: $(a) 0 \cdot 83,(b) 0 \cdot 79$, and (c) $0 \cdot 79$. Case $(a)$ does produce better correlation between the calculated and experimental values of $f_{p s}$. However from the statistical point of view, case (c) with $\varphi=9 \cdot 3$ can give a conservative estimate with about $84 \%$ of the population above it, and therefore this paper suggests adopting this value for design. In most cases, the quantity $\left(\varphi E_{p s} \varepsilon_{c u} A_{p s} / 0 \cdot 85 \beta_{1} f_{c}^{\prime} b_{w} L\right)$ in the denominator of the second term on the right-hand side of equation (21a) ranges from $0 \cdot 01$ to $0 \cdot 05$. Omitting this quantity will not have significant effect on the final result. In addition, the formula in equation (21b) for evaluation of $c_{p e}$ is not too practical. As the tendon stress $f_{p s}$ at ultimate is not known in advance, it is not convenient to judge whether the compression reinforcement reaches its yield strength and whether the neutral axis depth $c$ at ultimate is greater than the depth of compression flange $h_{f}$. In view of these, the value of $c_{p e}$ is redefined as $c_{p e}=\left(A_{p s} f_{p e}+A_{s} f_{y}\right) / 0 \cdot 85 \beta_{1} f_{c}^{\prime} b$ where $b$ is the width of compression zone. In addition, measures must be taken to ensure that equation (21) is applicable to continuous beams.

Using case $(c)$ for the parameter $\varphi$, taking the ultimate concrete compressive strain in the top fibre as $\varepsilon_{c u}=0.003$ and adopting the new definition for the parameter $c_{p e}$, equation (21) is rewritten as follows

$$
\begin{aligned}
f_{p s} & =f_{p e}+\frac{9.3 \times 0.003 \times E_{p s}\left(d_{p}-c_{p e}\right)}{l_{e}} \\
& =f_{p e}+\frac{0.0279 E_{p s}\left(d_{p}-c_{p e}\right)}{l_{e}} \leqslant f_{p y} \\
c_{p e} & =\frac{A_{p s} f_{p e}+A_{s} f_{y}}{0.85 \beta_{1} f_{c}^{\prime} b}
\end{aligned}
$$

where $b$ is the width of compression zone, and $l_{e}$ is the length of the tendon between the end anchorages divided by the number of plastic hinges $n$ required to develop a failure mechanism in the span under consideration.

It is seen that equation (25) is similar in form to equation (22), which is the design formula in the Canadian Code A23.3-94. ${ }^{26}$ Using both equation (25) and equation (22), the tendon stress $f_{p s}$ at ultimate for the specimens examined is again calculated. Correlation analyses of these calculated tendon stress $f_{p s}$ at ultimate were then carried out with the experimental results. Results of the correlation analyses for equations (25) and (22) are respectively plotted in Figs 5 and 6.

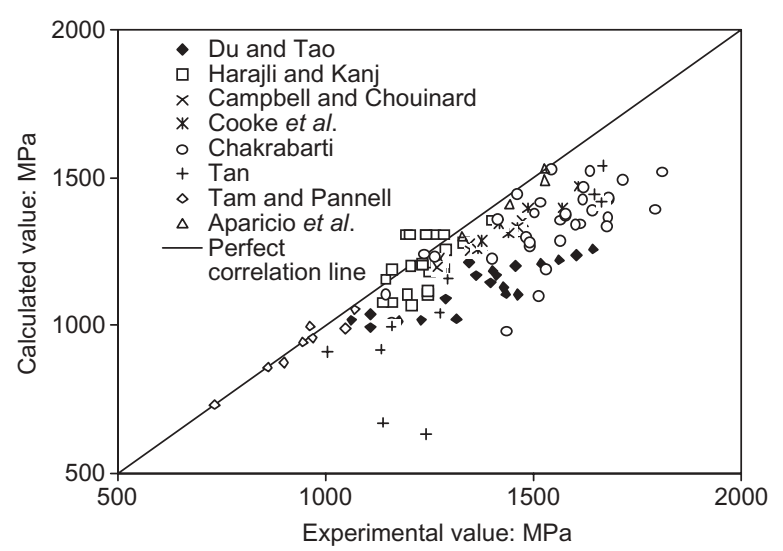

Fig. 5. Comparison of calculated values of $f_{p s}$ based on equation (25) against experimental values of $f_{p s}$

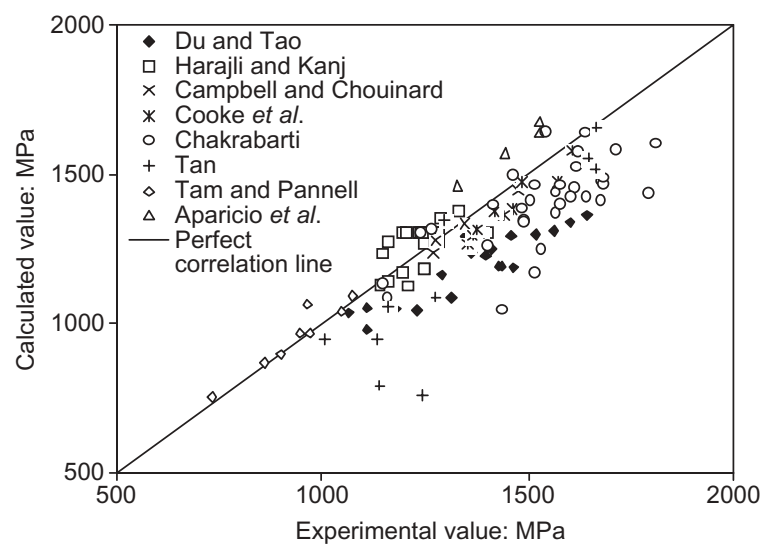

Fig. 6. Comparison of calculated values of $f_{p s}$ based on equation (22) against experimental values of $f_{p s}$

Magazine of Concrete Research, 2004, 56, No. 1 
The correlation coefficients for equations (25) and (22) are respectively $0 \cdot 79$ and $0 \cdot 81$. Although the correlation coefficient of equation (22) is a little bit better than that of equation (25), it can be observed in Fig. 6 that many of the predicted values of the tendon stress $f_{p s}$ at ultimate are on the unsafe side. Apart from being provided with reasonable safety, equation (25) is given explicitly in terms of the Young's modulus of tendon $E_{p s}$. Therefore it may also be applied to other types of tendons such as those made of fibre-reinforced polymer.

In the application of equation (25) to simply supported beams, the number of plastic hinges is $n=1$, and $l_{e}$ is equal to the total span length between the end anchorages $L$. In the corresponding analysis of continuous prestressed concrete beams with unbonded tendons, the number of plastic hinges $n$ depends on the loading pattern, namely the number and locations of spans loaded. Fig. 7 shows a two-span continuous prestressed concrete beam with unbonded tendons under a concentrated load on each span. Following the same arguments as before, the extension of the unbonded tendons is largely determined by the deformations of the beam at the plastic regions. The total length of equivalent plastic region in a continuous beam where prestressing tendons are only anchored at two ends is the sum of the equivalent lengths of the component plastic regions where plastic hinges form, as shown schematically in Fig. 7. Therefore the stress increment $\Delta f_{p s}$ in the tendon is proportional to the number of plastic hinges that can develop under a given pattern of loading between the anchors, as reflected in equation (25). For design purposes, the evaluation of the stress increment $\Delta f_{p s}$ in the tendon is often worked out assuming that a single end span is loaded, as this will give a lower bound value for $\Delta f_{p s}$. Thus in the design of such continuous beams, taking $n=2$ for evaluation of the stress increment $\Delta f_{p s}$ is on the safe side.

On the investigation of continuous members, Burns et $\mathrm{al}^{8}{ }^{8}$ tested two half-scale models of prototype oneway slab, continuous over three equal spans. The specimens, designated as slab A and slab B, were loaded with different loading patterns. The experimental values of the parameter $\varphi$ for these specimens under different loading patterns are calculated using equation (20) and listed in Table 2. If these experimental values of $\varphi$ are divided by $9 \cdot 3$ (i.e. the value for one plastic hinge), the parameter $n$ reflecting the number of plastic hinges is

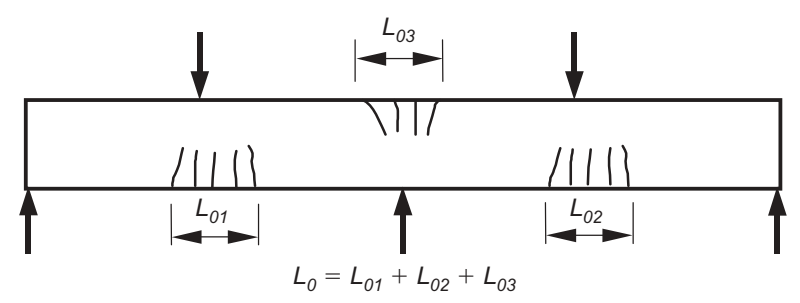

Fig. 7. Total length of equivalent plastic region $L_{0}$ in a continuous beam
Table 2. Possible number of plastic hinges $n$ in the tests of Burns et al. ${ }^{8}$

\begin{tabular}{l|c|c|c}
\hline Slab ID & Test no. & Parameter $\varphi$ & Parameter $n$ \\
\hline Slab A & 108 & $31 \cdot 1$ & $3 \cdot 3$ \\
& 109 & $39 \cdot 0$ & $4 \cdot 2$ \\
Slab B & 110 & $21 \cdot 0$ & $2 \cdot 3$ \\
& 208 & $41 \cdot 0$ & $4 \cdot 4$ \\
& 209 & $27 \cdot 0$ & $2 \cdot 9$ \\
& 210 & $25 \cdot 0$ & $2 \cdot 7$ \\
\hline
\end{tabular}

worked out and tabulated in Table 2. These calculated values of $n$ are all greater than 2 . It therefore reaffirms that taking $n=2$ is on the safe side.

\section{Comparison with the results of the Workshop on External Prestressing in 1993}

In 1993, the Association Francaise Pour la Construction (AFPC) organised the Workshop on Behaviour of External Prestressing in Structures in France. In addition, participants were invited to study numerically two cases using non-linear calculation methods of prestressed structures. The conference organisers gave details of a single-span beam and a continuous beam to be analysed, and participants were asked to provide prescribed forms of output, including curve of loaddeflection responses. Fourteen answers were received from all over the world, and a synthesis of the results received was presented in as an appendix volume of the proceedings. ${ }^{28}$ As the present study is focusing on the determination of ultimate tendon stress at flexural failure of prestressed concrete beams with unbonded tendons, only the ultimate loads of the beams in the AFPC workshop are calculated based on equation (25) and they are compared with the AFPC results.

Provided that the second-order effects of tendon eccentricity variation due to member deformation are small or negligible, equation (25) is still valid for externally prestressed concrete beams. The calculated ultimate load for the cast-in-place simple beam with $100 \%$ external prestressing is $2835 \mathrm{kN}$, and the comparison with the AFPC results is shown in Fig. 8. Generally speaking, the ultimate load based on equation (25) is around the middle of the AFPC results. For the cast-inplace continuous beam with $100 \%$ external prestressing, the calculated ultimate load is $1994 \mathrm{kN}$, and Fig. 9 shows the comparison with the AFPC results. Although the ultimate load for the continuous beam based on equation (25) is smaller than some of the AFPC results, it is still within the range spanned by them.

\section{Conclusion}

This paper examined various design methods for the determination of ultimate tendon stress at flexural 


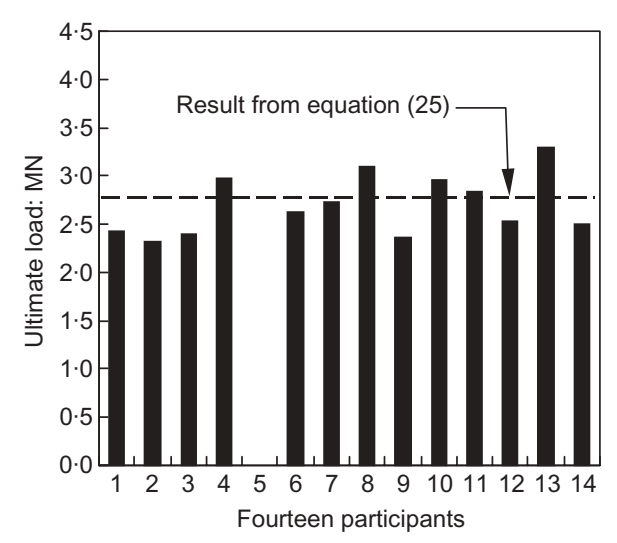

(a)

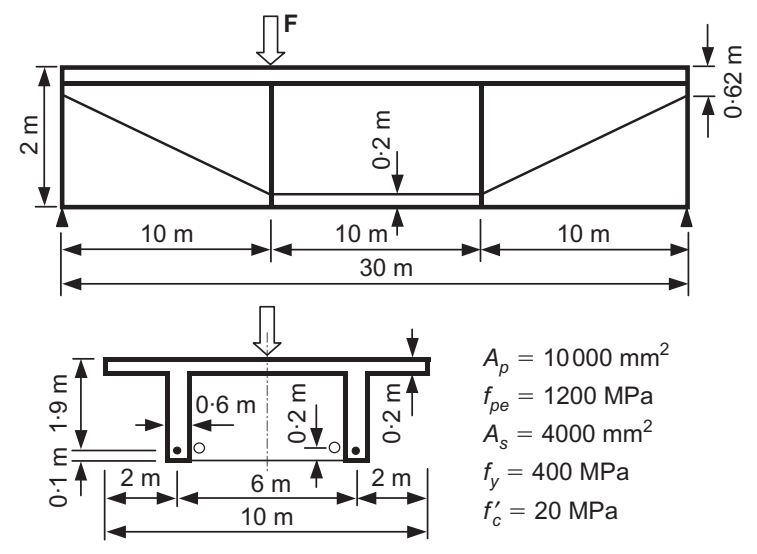

(b)

Fig. 8. Ultimate load of a single-span beam: (a) comparison of result from equation (25) with the AFPC results; (b) details of the beam

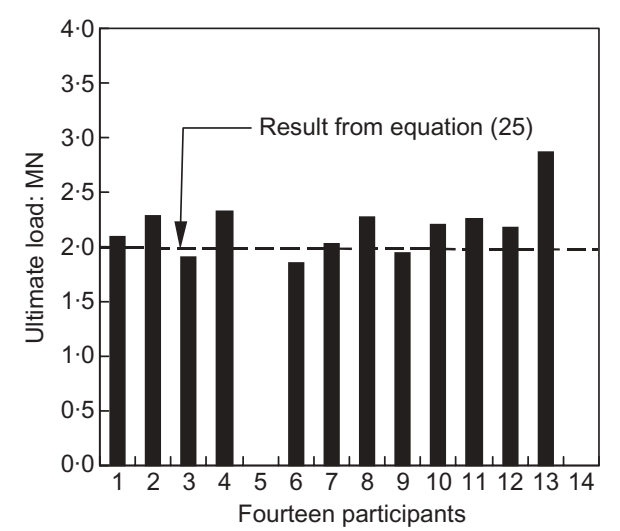

(a)
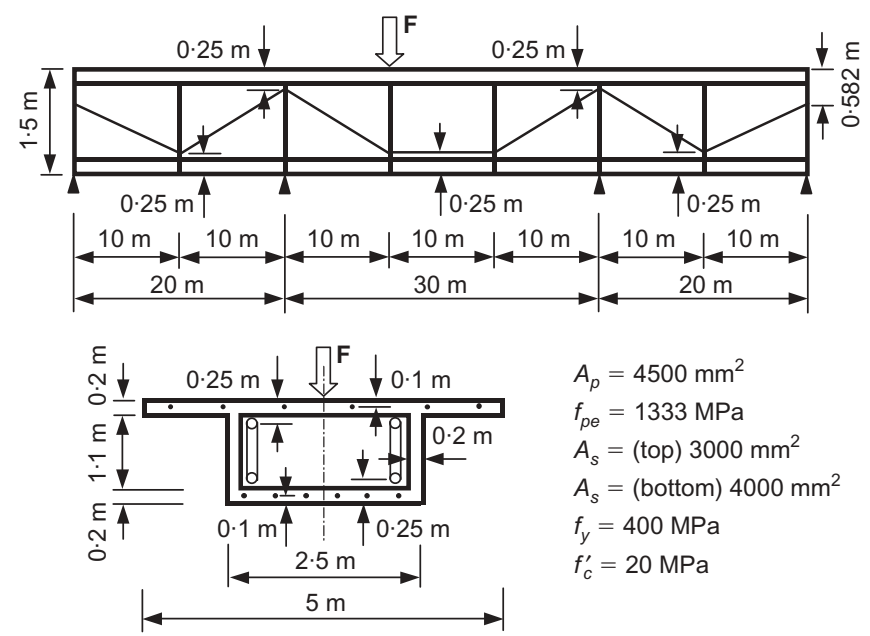

$A_{p}=4500 \mathrm{~mm}^{2}$

$f_{p e}=1333 \mathrm{MPa}$

$A_{s}=$ (top) $3000 \mathrm{~mm}^{2}$

$A_{s}=$ (bottom) $4000 \mathrm{~mm}^{2}$

$f_{y}=400 \mathrm{MPa}$

$f_{c}^{\prime}=20 \mathrm{MPa}$

Fig. 9. Ultimate load of a continuous beam: (a) comparison of result from equation (25) with the AFPC results; (b) details of the beam

failure of prestressed concrete beams with unbonded tendons. Two broad categories of deformation-based approaches have been identified, namely those based on the span-depth ratio together with loading type represented by Harajli's model ${ }^{11}$ and those based on the neutral axis depth represented by Pannell's model. ${ }^{4}$ These methods are reviewed critically. A new design formula has been proposed in the light of the available experimental data. The following conclusions are drawn.

(a) Harajli's model places much emphasis on the effects of loading type on stress increment in unbonded tendons at flexural failure of the beam. The ratio of equivalent length of plastic region to the total span length between end anchorages, namely $L_{0} / L$, is in essence another form of Baker's bond reduction coefficient $\lambda$. (b) In Pannell's model, the ratio of equivalent length of plastic region to neutral axis depth, namely the parameter $\varphi$, is taken as a constant after analysis of test results conducted by different investigators. Differences of the parameter $\varphi$ do exist in specific series of experiments as well as among experiments by different investigators. However such differences could also be attributed to different measurement methods, different failure criteria, etc. adopted by different investigators. Therefore provided that the predictions by taking the parameter $\varphi$ as a constant are supported by experimental results, this assumption is not unreasonable.

(c) In the search for a suitable value for the parameter $\varphi$, three values including $16 \cdot 1,10$ and $9 \cdot 3$ have been considered. Taking $\varphi=16 \cdot 1$ produces relatively better correlation between the calculated and experimental values of the tendon stress $f_{p s}$ at

Magazine of Concrete Research, 2004, 56, No. 1 
ultimate than the other two values. The other two choices of $\varphi=10$ and $\varphi=9 \cdot 3$ predict $f_{p s}$ on the safe side. From the statistical point of view, choosing $\varphi=9.3$ can ensure that about $84 \%$ of the predicted values of $f_{p s}$ to be on the safe side. Therefore this paper suggests adopting $\varphi=9 \cdot 3$ for practical use.

(d) Equation (25), which was obtained from simplification of equation (21), can be adopted to predict the value of the tendon stress $f_{p s}$ at ultimate in design. It is applicable not only to the conventional high-strength steel prestressing tendons, but also to those made of other materials such as fibre-reinforced polymer.

\section{Acknowledgement}

The authors are most grateful to Professor Carin L. Roberts-Wollmann, Department of Civil \& Environmental Engineering, Virginia Polytechnic Institute and State University for her help in locating Reference 28.

\section{References}

1. BAKER A. L. L. Plastic theory of design for ordinary reinforced and prestressed concrete including moment redistribution in continuous members. Magazine of Concrete Research, 1949, 1, No. 2, 57-66.

2. Janney J. R., Hognestad E. and McHenry D. Ultimate flexural strength of prestressed and conventionally reinforced concrete beams. ACI Journal, Proceedings, 1956, 52, No. 6, 601-620.

3. Warwaruk J., Sozen M. A. and Siess C. P. Investigation of prestressed reinforced concrete for highway bridges, part III: strength and behavior in flexure of prestressed concrete beams. Bulletin No. 464, Engineering Experiment Station, University of Illinois, Urbana, 1962, 105 pp.

4. Pannell F. N. The ultimate moment of resistance of unbonded prestressed concrete beams. Magazine of Concrete Research, 1969, 21, No. 66, 43-54.

5. Mattock A. H., Yamazaki J. and Kattula B. T. Comparative study of prestressed concrete beams with and without bond. $A C I$ Journal, 1971, 68, No. 2, 116-125.

6. TAM A. and PANnell F. N. Ultimate moment of resistance of unbonded partially prestressed reinforced concrete beams. Magazine of Concrete Research, 1976, 28, No. 97, 203-208.

7. Mojtahedi S. and Gamble W. L. Ultimate steel stresses in unbonded prestressed concrete. Journal of the Structural Division, ASCE, 1978, 104, No. 7, 1159-1165.

8. Burns N. H., Charney F. A. and Vines W. R. Test of one-way post-tensioned slabs with unbonded tendons. PCI Journal, 1978, 23, No. 5, 66-81.

9. Cooke N., PARK R. and Yong P. Flexural strength of prestressed concrete members with unbonded tendons. PCI Journal, 1981, 26, No.6, 52-80.

10. Du G. C. and TAO X. K. Ultimate stress of unbonded tendons in partially prestressed concrete beams. PCI Journal, 1985, 30, No. 6, 72-91.
11. Harajli M. H. Effect of span-depth ratio on the ultimate steel stress in unbonded prestressed concrete members. ACI Structural Journal, 1990, 87, No. 3, 305-312.

12. Campbell T. I. and ChOuinard K. L. Influence of non-prestressed reinforcement on the strength of unbonded partially prestressed concrete members. ACI Structural Journal, 1991, 88, No. 5, 546-551.

13. NaAman A. E. and Alkhairi F. M. Stress at unbonded posttensioned tendons: part 1 - evaluation of the state-of-the-art. ACI Structural Journal, 1991, 88, No. 5, 641-651.

14. NaAman A. E. and Alkhairi F. M. Stress at unbonded posttensioned tendons: part 2 - proposed methodology. ACI Structural Journal, 1991, 88, No. 6, 683-692.

15. HaRAJli M. H. and KANJ M. Y. Ultimate flexural strength of concrete members prestressed with unbonded tendons. ACI Structural Journal, 1991, 88, No. 6, 663-673.

16. Chakrabarti P. R. Ultimate stress for unbonded post-tensioning tendons in partially prestressed beams. ACI Structural Journal, 1995, 92, No. 6, 689-697.

17. TAN K. H. and NG C. K. Effects of deviators and tendon configuration on behavior of externally prestressed beams. ACI Structural Journal, 1997, 94, No. 1, 13-22.

18. Allouche E. N., Campbell T. I., Green M. F. and Soudki K. A. Tendon stress in continuous unbonded prestressed concrete members - part 1: review of literature. PCI Journal, 1998, 43, No. 6, 86-93.

19. Allouche E. N., Campbell T. I., Green M. F. and Soudki K. A. Tendon stress in continuous unbonded prestressed concrete members - part 2: parametric study. PCI Journal, 1999, 44, No. $1,60-73$.

20. Lee L. H., Moon J. H. and Lim J. H. Proposed methodology for computing of unbonded tendon stress at flexural failure. ACI Structural Journal, 1999, 96, No. 6, 1040-1048.

21. Tan K. H., Faroog M. A. A. and NG C. K. Behavior of simplespan reinforced concrete beams locally strengthened with external tendons. ACI Structural Journal, 2001, 98, No. 2, 174-183.

22. Aparicio A. C., Ramos G. and Casas J. R. Testing of externally prestressed concrete beams. Engineering Structures, 2002, 24, No. 1, 73-84.

23. American Concrete Institute. Building Code Requirements for Reinforced Concrete (ACI) 318-83). ACI, Detroit, 1983, 111 $\mathrm{pp}$.

24. British Standards Institution. 1985, BSI 8110 - part 1, 2 and 3.

25. American Association of State Highway and TransporTATION Officals. AASHTO LRFD Bridge Design Specification, SI Unit 1st edn. 1994.

26. Canadian Standards Association, Design of Concrete Structures CSA, Rexdale, Ontario, 1994, A23.3-94.

27. American Concrete Institute. Building Code Requirements for Reinforced Concrete (ACI 318-95) and Commentary (318R95). ACI, Farmington Hills, MI, 1995, 369 pp.

28. Conti E. and TARdy R. External Prestressing in Structures: Proceedings of the Workshop on Behaviour of External Prestressing in Structures (E. Conti and B. Foure (eds)) SaintRemy-les-Chevreuse, France, 9-12th June, 1993.

Discussion contributions on this paper should reach the editor by 1 August 2004 